\title{
Towards the Visual Sciences ${ }^{\dagger}$
}

\section{Vito Cardone}

President UID-Unione Italiana Disegno, 00186 Rome, Italy; presidenza@unioneitalianadisegno.it

+ Presented at the International and Interdisciplinary Conference IMMAGINI? Image and Imagination between Representation, Communication, Education and Psychology, Brixen, Italy, 27-28 November 2017.

Published: 14 March 2018

I would like to thank Alessandro Luigini for the idea and for the organization of this event; thanks to the principal, who preceded me, for the hospitality and for his kind words.

We have talked many times with Alessandro about this meeting, which the Italian Union for Design has gladly sponsored. I can say that we had been waiting for an event like this for years. For at least twenty years, we have been questioning, perhaps rather slowly and perhaps not only us, the role of images in contemporary society and our role within the Italian university.

I liked the idea very much, right away. I also liked the title and logo, with the double question mark, one turned upside down, which can be interpreted in many ways. Some things have already been said, in the poster by the organizers themselves and by Luigini at the beginning. I wish only to underline that, apart from the writing in Spanish, which I particularly like, I enjoy reading the exaltation of doubt, rather than certainties; of doubt as a formidable thrust in the unstoppable and interminable path in the search for truth.

I am convinced, and have been for more than twenty years precisely, that the specific of our scientific-disciplinary area, in Italy, is not and should no longer be the only representation of architecture, territory and works of art, but the elaboration of visual images as a whole.

When I was not yet President of the UID [1]-and I was not therefore obliged to mediate and synthesize the different positions, but could take on myself clear positions and more lively attitudes-I had great quarrels about it, even with dear friends, like Mario Manganaro, a beloved colleague who left us last year. About fifteen years ago, on the occasion of one of the many conferences that the UID held in Lerici, to its statement that "our specific architecture is" I replied abruptly, without a minimum of diplomacy: "no, our specific it is the definition of graphic images, of any nature, not only those connected to architecture". Even today, that categorical and firm answer resonates in me; but I am increasingly convinced that this is so.

I do not claim the paternity of that position, which I saw slowly emerging in the scientific community of graphic representation, on an international level, since the end of the last century. So, considering also that we receive and acquire, more than three-quarters-or, according to the most cautious, at least two-thirds - of the information we store through images, some teachers of the graphic expression area, above all of the engineering area, identified wide unpublished and unifying spaces for the disciplinary areas of graphic representation, centered precisely on images. In particular, Gary Bertoline re-established the existence of cultural foundations for a single body of knowledge necessary for an emerging discipline that he called visual science: the basis of which he identified in three areas-spatial cognition, imaging, geometry-and whose applications are identified as being in two sectors: artistic and technical.

I simply accepted, acquired and shared this approach and helped to introduce it in Italy, where unfortunately it is still very difficult to establish it. In part, this is due to the logic of "own" gardens and to the closure of scientific-disciplinary sectors.

The area of graphic representation in architecture and civil engineering is clearly distinguished from that which is homologous to other types of engineering. Fortunately, even if with great delay, 
something is also beginning to develop in Italy, within our scientific society and in the other areas of graphic representation.

Luigini's work is in this direction. It resumes what some of us started at the beginning of this new millennium, when the new courses of study in Primary Education Science were established, which almost all the major universities activated, with lessons from our scientific-disciplinary sector. In some academic realities, these were contracted to professors of the Academies of Fine Arts, in others to colleagues of our SSD (Settore Scientifico Disciplinare) [2], who pursued them on a personal basis, without any connection between them.

At the University of Salerno, the task was entrusted to Carla Carluccio, research architect of the Faculty of Engineering, who-thanks also to the authority I had as headmaster of this faculty, the most powerful of the University - it was the first one taught by a colleague of our SSD in Educational Sciences, where in fact she moved and was then given the position of associate professor. Carla had, however, little time before retirement, so, although she organized some seminars and published various works on the subject, she did not commit herself continually and pro-visively, as would have been desirable. Her latest work was an interesting book with Valeria Nuzzo, her pupil and present at this conference.

No other colleagues engaged in Science of Formation maintained links; the most experienced, founding scholars left the teaching to their young collaborators, who each worked for his or her own business.

The situation seems to have finally changed with Luigini, a new instructor of the sector, who is young, motivated, and enterprising. Already, he has published a very interesting book: a collection of seven seminars and reflections, held by scholars of drawing, on primary education science degree courses.

I really appreciate his effort. He has ploughed the soil and planted seeds. This conference is a good omen and I hope it will give rise to a periodic approach; we need to develop these issues with continuity and diligence, to meet with other disciplinary and scientific areas, inside and outside the Educational Science area.

This year, in the annual meeting of the Academics of the Disciplines of the Representation, held in Naples, with ever-increasing success, we have addressed the theme of "territories and frontiers of representation". At this meeting, some papers were presented that are both relevant to the past and the present. Next year, in Milan, we will talk about "matter-le/immaterial" through images and these themes will undoubtedly still have a lot to offer. It will be our 40th Conference and we are also going to celebrate our 40th anniversary of our scientific society, which will fall two years later. Our scientific society is perhaps the oldest, as well as the largest, of the whole cultural area 08 of the CUN [3].

It was once said that one becomes an adult at forty. Well, if we succeed in developing these themes, by making this appointment periodic and by centering the various meetings on more circumscribed themes, after this initial introduction, inevitably of a very general nature; if we dedicate ourselves with the determination and passion we see today, with the involvement of young talent also in the design of the initiatives-I really appreciate the participation of young colleagues and scholars in the Scientific Committee of this Conference-we will see the results. And we will be able to say that we have finally reached adulthood and maturity.

\section{References and Notes}

1. UID, Italian Union of Design, Scientific Society of the Academics of the Representation Founded for about 40 years.

2. In Italy Every Scholars are Classified in the Ministry of Education and Research in Disciplinary Scientific Sectors (SSD). The Scientific Disciplinary Sector to which the Scientific Society UID Belongs is ICAR17Disegno.

3. The Scientific Disciplinary Sectors Are organized in Macro Areas and 08 is the Area of Civil Engineering and Architecture. The CUN is the National University Council. 